\title{
Trends in low-density lipoprotein cholesterol level among Chinese young adults hospitalized with first acute myocardial infarction
}

\author{
Min Zhang ${ }^{1 \wedge}$, Hui-Juan Zuo ${ }^{2}$, Hong-Xia Yang ${ }^{1}$, Nan Nan $^{1}$, Dongfeng Zhang ${ }^{1}$, Xian-Tao Song ${ }^{1}$ \\ ${ }^{1}$ Department of Cardiology, Beijing Anzhen Hospital, Capital Medical University, Beijing, China; ${ }^{2}$ Department of Community Health Research, \\ Beijing Anzhen Hospital, Capital Medical University, Beijing Institute of Heart Lung and Blood Vessel Diseases, Beijing, China \\ Contributions: (I) Conception and design: M Zhang, HJ Zuo, XT Song; (II) Administrative support: XT Song; (III) Provision of study materials or \\ patients: M Zhang, XT Song; (IV) Collection and assembly of data: HX Yang, N Nan, D Zhang; (V) Data analysis and interpretation: M Zhang, HJ \\ Zuo; (VI) Manuscript writing: All authors; (VII) Final approval of manuscript: All authors. \\ Correspondence to: Xian-Tao Song. Department of Cardiology, Beijing Anzhen Hospital, Capital Medical University, Beijing 100029, China. \\ Email: songxiantao0929@qq.com; Hui-Juan Zuo. Beijing Anzhen Hospital, Capital Medical University, Beijing Institute of Heart Lung and Blood \\ Vessel Disease, 2 Anzhen Road, Chaoyang District, Beijing 100029, China. Email: huijuanzuo@sina.com.
}

Background: Representative data has shown a linear increase in mean low-density lipoprotein cholesterol (LDL-C) levels among Chinese adults, contributing to the burden of atherosclerotic cardiovascular disease (ASCVD). This study aimed to assess the trends in LDL-C levels and their association with coronary artery stenosis during the first acute myocardial infarction (AMI) in young Chinese adults.

Methods: A retrospective study including 2,781 adults, aged 18-44 years, hospitalized for their first AMI in Beijing Anzhen hospital between 2007 and 2017 was performed.

Results: Mean LDL-C level was $2.82 \pm 0.97 \mathrm{mmol} / \mathrm{L}$ with the prevalence of elevated LDL-C being $21.6 \%$ $(601 / 2,781)$. Of the study, only $4.2 \%$ were aware of their elevated LDL-C status. Neither mean LDL-C concentration nor prevalence of elevated LDL-C showed a downward trend between 2007 and $2017(\mathrm{P}>0.05)$. Patients aged $<35$ years had the highest LDL-C level and frequency of elevated LDL-C among the three age groups (aged $<35,35-39$, and 40-44 years; $\mathrm{P}<0.01$ ). Patients with LDL-C $\geq 3.4 \mathrm{mmol} / \mathrm{L}$ evinced a more than $50 \%$ increased risk of coronary artery stenosis compared with those with $\mathrm{LDL}-\mathrm{C}<1.4 \mathrm{mmol} / \mathrm{L}$ [adjusted odds ratio (OR) 3.19; 95\% confidence interval (CI): 1.62 to 6.29]. Of the study, $62.0 \%$ had at least two conventional risk factors (RFs), and smoking, accompanied by hypertension, obesity, or elevated LDL-C were the most common combinations.

Conclusions: The current study provides an overview of trends in LDL-C level and elevated LDL-C among young adults at the time of first AMI. Patients had a high prevalence of elevated LDL-C but low awareness of this status. Coronary artery stenosis was positively correlated with LDL-C level. Preventive strategies, including public education regarding cholesterol levels and benefits of maintaining LDL-C below $3.4 \mathrm{mmol} / \mathrm{L}$ should be considered for young adults as a primary preventive strategy.

Keywords: Acute myocardial infarction (AMI); low-density lipoprotein cholesterol (LDL-C); risk factor (RF); dyslipidemia

Submitted Aug 06, 2021. Accepted for publication Oct 21, 2021.

doi: $10.21037 /$ atm-21-4480

View this article at: https://dx.doi.org/10.21037/atm-21-4480

^ ORCID: 0000-0001-6201-3585. 


\section{Introduction}

Stroke and ischemic heart disease are now the leading causes of death in China, ahead of cancer and other diseases (1). There has been an especially rapid rise in the incidence of acute coronary events and hospitalization rates among young adults $(2,3)$. The proportion of young adults hospitalized for coronary heart disease has been estimated at approximately $10 \%$ (4). This trend parallels an increase in cardiovascular risk factors (RFs), including smoking, hypertension, diabetes, obesity, and dyslipidaemia (5). Cohort studies have provided coherent and consistent evidence that plasma low-density lipoprotein cholesterol (LDL-C) concentration shows a strong and linear logarithmic relationship with risk of incident atherosclerotic cardiovascular disease (ASCVD) events $(6,7)$. Indeed, LDL-C level is the third leading RF for death from cardiovascular disease in China, after hypertension and a high-salt diet (1).

The LDL-C is not only a biomarker of increased risk but also a causal factor in the pathophysiology of ASCVD (7). It transports cholesterol from the liver to peripheral tissues and causes the transformation of macrophages into foam cells within the arterial wall, a step central to atherosclerosis. Nationally representative data has shown a linear increase in mean LDL-C levels, from $2.12 \mathrm{mmol} / \mathrm{L}$ in 2002 to $2.78 \mathrm{mmol} / \mathrm{L}$ in 2010 and $2.87 \mathrm{mmol} / \mathrm{L}$ in 2015 , among Chinese adults aged $\geq 18$ years. The frequency of dyslipidemia increased in a similarly linear manner during the same time period. In particular, hypercholesterolemia increased from $1.6 \%$ [2002] to $5.6 \%$ [2010] and to $5.8 \%$ [2015] (8) contributing to the burden of ASCVD. Therefore, effective measures to control LDL-C represent an urgent public health priority (9).

More data is required, both from young adults in the general population and from young adults with a first AMI, to formulate preventive strategies for ASCVD in this age group. Few studies have evaluated long-term trends and prevalence of elevated LDL-C during a first AMI in young adults in China. Therefore, we investigated LDL-C level and its changing trends in young adults hospitalized with first AMI between 2007 and 2017. The current study presents an overview of trends and prevalence of elevated LDL-C and its relationship with the degree of coronary artery stenosis. Our findings provide a reference point for the development of preventive strategies in the young Chinese population. We present the following article in accordance with the STROBE reporting checklist (available at https://dx.doi.org/10.21037/atm-21-4480).

\section{Methods}

\section{Participants}

The current study was a retrospective, single-center analysis of young men hospitalized for a first AMI. Clinical and demographic data were collected from Beijing Anzhen hospital records by trained abstractors, using physician notes, laboratory reports, patient histories, and discharge summaries for the period between January 2007 and December 2017. A total of 2,739 young adults aged 18-44 years hospitalized for a first AMI were identified and recruited. Hospitalizations were determined according to the fourth universal definition of MI (10). Patients with following conditions were excluded from the study: (I) history of MI, percutaneous coronary intervention, coronary artery bypass grafting, post-AMI syndrome, chronic ischemic heart disease, heart transplants, heart failure (HF), arteritis, congenital heart disease, and cancer; (II) cases without coronary angiography or with missing values for laboratory reports. All procedures performed in this study involving human participants were in accordance with the Declaration of Helsinki (as revised in 2013). This study was approved by Beijing Anzhen Hospital Ethics Committee (2020049X). Individual consent for this retrospective analysis was waived.

\section{Measurements and diagnostic criteria}

Established criteria were used as the basis for defining AMI, including: detection of a rise and/or fall of cardiac biomarker values [preferably cardiac troponin (cTn)] with at least one value above the 99th percentile upper reference limit (URL). In addition, at least 1 of the following had to be present: (I) ischemia; (II) new or presumed new significant ST-segment-T wave (ST-T) changes or new left bundle branch block; (III) development of pathological Q waves in the electrocardiogram (ECG); (IV) imaging evidence of new loss of viable myocardium or new regional wall motion abnormality; (V) evidence of intracoronary thrombus by angiography or autopsy. The AMI was classified as either ST-segment elevation myocardial infarction (STEMI) or non-STEMI (NSTEMI). Coronary artery disease was defined as main coronary artery stenosis $\geq 50 \%$ confirmed by coronary angiography, involving left main coronary artery (LMT), left anterior descending branch (LAD), left 
Table 1 Baseline characteristics of the study population

\begin{tabular}{|c|c|}
\hline Characteristics & Overall $(n=2,781)$ \\
\hline \multicolumn{2}{|l|}{ Gender } \\
\hline Male & $2,657(95.5)$ \\
\hline Female & $124(4.5)$ \\
\hline \multicolumn{2}{|l|}{ Age (y) } \\
\hline$<35$ & $463(16.6)$ \\
\hline $35-39$ & $768(27.6)$ \\
\hline $40-44$ & $1,550(55.7)$ \\
\hline \multicolumn{2}{|l|}{ AMI subtypes } \\
\hline STEMI & 2,148 (77.2) \\
\hline NSTEMI & $633(22.8)$ \\
\hline \multicolumn{2}{|l|}{ Number of vessels involved } \\
\hline $\begin{array}{l}\text { Without significant coronary stenosis or } \\
\text { normal }\end{array}$ & $255(9.2)$ \\
\hline Single vessel disease & $1,235(44.4)$ \\
\hline Multi-vessel coronary disease & $1,291(46.4)$ \\
\hline \multicolumn{2}{|l|}{ Risk factors } \\
\hline Smoking & $2,020(72.6)$ \\
\hline Hypertension & $1,139(41.0)$ \\
\hline Obesity & 1,063 (38.2) \\
\hline Elevated LDL-C & $601(21.6)$ \\
\hline Diabetes & $424(15.2)$ \\
\hline \multicolumn{2}{|l|}{ Numbers of conventional RFs } \\
\hline 0 & $210(7.6)$ \\
\hline 1 & $846(30.4)$ \\
\hline 2 & $954(34.3)$ \\
\hline 3 & $601(21.6)$ \\
\hline 4 & $160(5.8)$ \\
\hline 5 & $10(0.4)$ \\
\hline
\end{tabular}

Data are presented as mean \pm standard deviation or $\mathrm{n}(\%)$. AMI, acute myocardial infarction; NSTEMI, non-ST-segment elevation myocardial infarction; STEMI, ST-segment elevation myocardial infarction; RFs, risk factors; LDL-C, low-density lipoprotein cholesterol.

circumflex branch (LCX), or right coronary artery (RCA). Prevalent hypertension and diabetes were defined based on a documented history in medical records. Elevated LDL-C was defined as LDL-C concentration $\geq 3.4 \mathrm{mmol} / \mathrm{L}$
$(130 \mathrm{mg} / \mathrm{dL})$. Obesity was defined as a body mass index $(\mathrm{BMI}) \geq 28 \mathrm{~kg} / \mathrm{m}^{2}$. Smokers were defined as those who reported smoking cigarettes for $>6$ months.

\section{Statistical analysis}

Categorical variables were expressed as total numbers (proportions). Differences in RF prevalence across age groups were compared using chi-square tests for categorical variables and trends in the prevalence of elevated LDL-C were analyzed using linear-by-linear association. The LDL-C levels were presented as mean \pm standard deviation (SD), Student's $t$-test was used to compare two independent samples and one-way analysis of variance (ANOVA) was used to compare 3 or more groups. Odds ratios (ORs) with 95\% CIs for associations were derived from multivariable logistic regression. All reported $\mathrm{P}$ values were 2-sided. Statistical analysis was performed using the software SPSS 25.0 (IBM Corp., Armonk, NY, USA).

\section{Results}

A total of 2,781 cases of first AMI hospitalizations in young adults (male: $\mathrm{n}=2,657$; female: $\mathrm{n}=124$ ) between 1 January 2007 and 31 December 2017 were identified. Of the 2,781, $463(16.6 \%)$ patients were $<35$ years, $768(27.6 \%)$ were $35-39$ years, and $1,550(55.7 \%)$ were $40-44$ years. The most frequent presentation of AMI was STEMI (77.2\%) and 1,291 (46.4\%) had multi-vessel coronary disease. Baseline characteristics of the overall sample and age subgroups are presented in Table 1. The most prevalent RFs were smoking $(72.6 \%)$, followed by hypertension $(41.0 \%)$, and obesity (38.2\%). The proportion of patients without any of the 5 conventional CVD RFs was $7.5 \%$ and $62.0 \%$ of patients had at least two RFs. Smoking accompanied by hypertension, obesity, or elevated LDL-C were the most common combinations (Table S1).

\section{Prevalence and awareness status of bypercholesterolemia}

Of the study, 756 patients (27.2\%) had hypercholesterolemia with total cholesterol (TC) $\geq 5.2 \mathrm{mmol} / \mathrm{L}$ or LDL-C $\geq 3.4 \mathrm{mmol} / \mathrm{L}$. There were significant differences in frequency of hypercholesterolemia across age groups, in numbers of patients combining hypercholesterolemia with other conventional RFs, and in the degree of coronary artery stenosis $(\mathrm{P}<0.05)$. Among individuals with hypercholesterolemia, $4.2 \%(32 / 756)$ were aware of 


\section{Page 4 of 9}

Table 2 The prevalence and the status of awareness of hypercholesterolemia

\begin{tabular}{|c|c|c|c|c|}
\hline \multirow{2}{*}{ Description } & \multicolumn{2}{|c|}{$\begin{array}{c}\text { Prevalence of } \\
\text { hypercholesterolemia }\end{array}$} & \multicolumn{2}{|c|}{$\begin{array}{c}\text { Awareness of } \\
\text { hypercholesterolemia }\end{array}$} \\
\hline & n (\%) & $P$ value & n (\%) & $P$ value \\
\hline Gender & & 0.444 & & 1.000 \\
\hline Male & 726 (27.3) & & 31 (4.1) & \\
\hline Female & $30(24.2)$ & & $1(3.3)$ & \\
\hline Age (y) & & $<0.001$ & & 0.544 \\
\hline$<35$ & 165 (35.6) & & $5(3.0)$ & \\
\hline 35-39 & $206(26.8)$ & & $11(5.3)$ & \\
\hline $40-44$ & $385(24.8)$ & & $16(4.2)$ & \\
\hline $\begin{array}{l}\text { Combination with } \\
\text { other RFs }\end{array}$ & & 0.031 & & 0.679 \\
\hline 0 & $62(23.5)$ & & $1(1.6)$ & \\
\hline 1 & $250(24.9)$ & & $10(4.0)$ & \\
\hline 2 & $292(30.1)$ & & $13(4.5)$ & \\
\hline$\geq 3$ & $152(28.0)$ & & $8(5.3)$ & \\
\hline $\begin{array}{l}\text { Coronary artery } \\
\text { stenosis }\end{array}$ & & $<0.001$ & & 1.000 \\
\hline$<50 \%$ & $38(5.0)$ & & 1 (2.6) & \\
\hline$\geq 50 \%$ & $718(95.0)$ & & 31 (4.3) & \\
\hline
\end{tabular}

RFs, risk factors.

their condition. There were no significant differences of awareness across gender, different age groups, numbers combining hypercholesterolemia with other conventional $\mathrm{RFs}$, or with the degree of coronary artery stenosis (Table 2).

\section{Correlation of LDL-C level with other characteristics}

Mean LDL-C level was $2.82 \pm 0.97 \mathrm{mmol} / \mathrm{L}$. Higher levels were observed in patients who were male, under 35 years, had a coronary artery stenosis $\geq 50 \%$ or had at least 1 other RF than in those who were female, 35-39 years or $40-44$ years, had a coronary artery stenosis $<50 \%$ and were without any of the 4 other conventional RFs $(\mathrm{P}<0.05)$. The prevalence of elevated LDL-C was $21.6 \%(601 / 2,781)$. In addition, 3.6\% $(99 / 2,781)$ had an LDL-C concentration of $<1.4 \mathrm{mmol} / \mathrm{L}$ and $3.8 \%(105 / 2,781)$ had elevated LDL-C together with at least three other conventional RFs. Patients who were aged $<35$ years and had a coronary artery stenosis $\geq 50 \%$ had a higher prevalence of elevated LDL-C (Table 3).
Zhang et al. Trends in low-density lipoprotein cholesterol level

\section{Correlation of LDL-C level with the degree of coronary artery stenosis}

Logistic regression analysis was performed using the presence of coronary artery stenosis $\geq 50 \%$ as the dependent variable. Coronary artery stenosis correlated with LDL-C level after adjustment for gender, age group, and combination with other RFs. Patients with LDL-C $<1.4 \mathrm{mmol} / \mathrm{L}$ were considered the reference. The odds ratio $(\mathrm{OR})$ was 3.19 [95\% confidence interval $(\mathrm{CI}): 1.62$ to 6.29] for patients with an LDL-C $\geq 3.4 \mathrm{mmol} / \mathrm{L}$. Increased risks were not associated with LDL-C levels of 1.4-1.79, $1.8-2.59$, and $2.6-3.39 \mathrm{mmol} / \mathrm{L}$ compared with the reference. Patients combining elevated LDL-C level with other conventional RFs had a significantly increased risk of coronary artery stenosis $\geq 50 \%$. The OR was 1.88 for patients with $1 \mathrm{RF}, 3.00$ for patients with $2 \mathrm{RFs}$, and 5.04 for patients with at least 3 RFs (Table 4).

\section{Trends of $L D L-C$ level and frequency of occurrence of elevated LDL-C}

Trends for the prevalence of elevated LDL-C are shown in Figure 1A. The prevalence of elevated LDL-C decreased from 2007 to 2017 but a downward trend in LDL-C concentration was not observed $(\mathrm{P}=0.068)$. The period between 2007 and 2009 revealed the highest increases in frequency of elevated LDL-C from $22.6 \%$ to $29.8 \%$ and was followed by a decrease in 2010 (17.4\%). Thereafter, little change was observed.

For mean LDL-C levels, no linear correlation with the time of admission was observed $(\beta=-0.019, \mathrm{P}=0.092)$. The period between 2008 and 2009 revealed the highest rate of decrease, from 3.05 to $2.75 \mathrm{mmol} / \mathrm{L}$, and thereafter, little change was observed (Figure 1B).

\section{Discussion}

The results of the present study indicate that young adults with a first hospitalization for AMI in China had a high prevalence rate of elevated LDL-C but a low awareness of their cholesterol status. The LDL-C level and prevalence of elevated LDL-C among the study decreased from 2007 to 2017 but without showing a consistent downward trend. Elevated LDL-C accompanied by smoking constituted the most common RF profile among patients who had at least two RFs. Patients with LDL-C $\geq 3.4 \mathrm{mmol} / \mathrm{L}$ had increased risk of coronary artery stenosis. 
Table 3 LDL-C level across different characteristics

\begin{tabular}{|c|c|c|c|c|c|c|c|c|}
\hline Description & $\begin{array}{c}\text { Mean LDL-C } \\
(\mathrm{mmol} / \mathrm{L})\end{array}$ & $P$ value & \multicolumn{6}{|c|}{ LDL-C level (mmol/L) } \\
\hline Gender & & 0.039 & & & & & & 0.001 \\
\hline Male & $2.83 \pm 0.96$ & & $89(3.3)$ & $217(8.2)$ & $869(32.7)$ & $907(34.1)$ & $577(21.7)$ & \\
\hline Female & $2.64 \pm 1.05$ & & $10(8.1)$ & $20(16.1)$ & $38(30.6)$ & $32(25.8)$ & $24(19.4)$ & \\
\hline Age (y) & & $<0.001$ & & & & & & 0.001 \\
\hline $35-39$ & $2.77 \pm 0.94$ & & $28(3.6)$ & $75(9.8)$ & $263(34.2)$ & $242(31.5)$ & $160(20.8)$ & \\
\hline $40-44$ & $2.77 \pm 0.91$ & & $61(3.9)$ & $126(8.1)$ & $515(33.2)$ & $542(35.0)$ & $306(19.7)$ & \\
\hline AMI subtype & & 0.065 & & & & & & 0.083 \\
\hline STEMI & $2.80 \pm 0.95$ & & $77(3.6)$ & $183(8.5)$ & $721(33.6)$ & 727 (33.8) & $440(20.5)$ & \\
\hline$\geq 50 \%$ & $2.85 \pm 0.98$ & & $84(3.3)$ & $205(8.1)$ & $810(32.1)$ & $856(33.9)$ & $571(22.6)$ & \\
\hline Combination with other RFs & & 0.023 & & & & & & 0.002 \\
\hline 0 & $2.69 \pm 1.07$ & & $16(6.1)$ & $36(13.6)$ & $94(35.6)$ & $64(24.2)$ & $54(20.5)$ & \\
\hline 1 & $2.82 \pm 1.00$ & & $42(4.2)$ & $86(8.6)$ & $323(32.1)$ & 341 (33.9) & $213(21.2)$ & \\
\hline 2 & $2.88 \pm 0.97$ & & $27(2.8)$ & $72(7.4)$ & 306 (31.5) & 336 (34.6) & 229 (23.6) & \\
\hline$\geq 3$ & $2.77 \pm 0.83$ & & $14(2.6)$ & 43 (7.9) & $184(33.9)$ & $196(36.2)$ & 105 (19.4) & \\
\hline
\end{tabular}

Data are presented as $\mathrm{n}(\%)$, mean \pm standard deviation or median. AMI, acute myocardial infarction; NSTEMI, non-ST-segment elevation myocardial infarction; STEMI, ST-segment elevation myocardial infarction; RFs, risk factors; LDL-C, low-density lipoprotein cholesterol.

Table 4 Logistic regression analysis on coronary artery stenosis in relationship to LDL-C level

\begin{tabular}{|c|c|c|c|c|}
\hline Factors & Crude OR $(95 \% \mathrm{Cl})$ & $P$ value & Adjusted OR (95\% Cl) & $P$ value \\
\hline Gender & $2.24(1.39-3.63)$ & 0.001 & $1.68(1.01-2.78)$ & 0.045 \\
\hline \multicolumn{5}{|l|}{ Age group } \\
\hline $35-39$ & $1.62(1.12-2.33)$ & 0.01 & $1.69(1.16-2.45)$ & 0.006 \\
\hline $40-44$ & $1.75(1.26-2.42)$ & 0.001 & $1.85(1.33-2.58)$ & $<0.001$ \\
\hline 0 & 1 & & 1 & \\
\hline 1 & $1.88(1.31-2.71)$ & 0.01 & $1.71(1.17-2.49)$ & 0.005 \\
\hline 2 & $3.00(2.03-4.45)$ & $<0.001$ & 2.67 (1.78-3.99) & $<0.001$ \\
\hline$\geq 3$ & $5.04(3.02-8.42)$ & $<0.001$ & $4.38(2.60-7.40)$ & $<0.001$ \\
\hline $1.8-2.59$ & $1.49(0.83-2.69)$ & 0.183 & $1.32(0.72-2.41)$ & 0.373 \\
\hline $2.6-3.39$ & $1.89(1.04-3.42)$ & 0.036 & $1.61(0.87-2.96)$ & 0.130 \\
\hline$\geq 3.4$ & $3.40(1.76-6.59)$ & $<0.001$ & $3.19(1.62-6.29)$ & $<0.001$ \\
\hline
\end{tabular}

OR, odds ratio; $\mathrm{Cl}$, confidence interval; RFs, risk factors; LDL-C, low-density lipoprotein cholesterol. 


\section{Page 6 of 9}
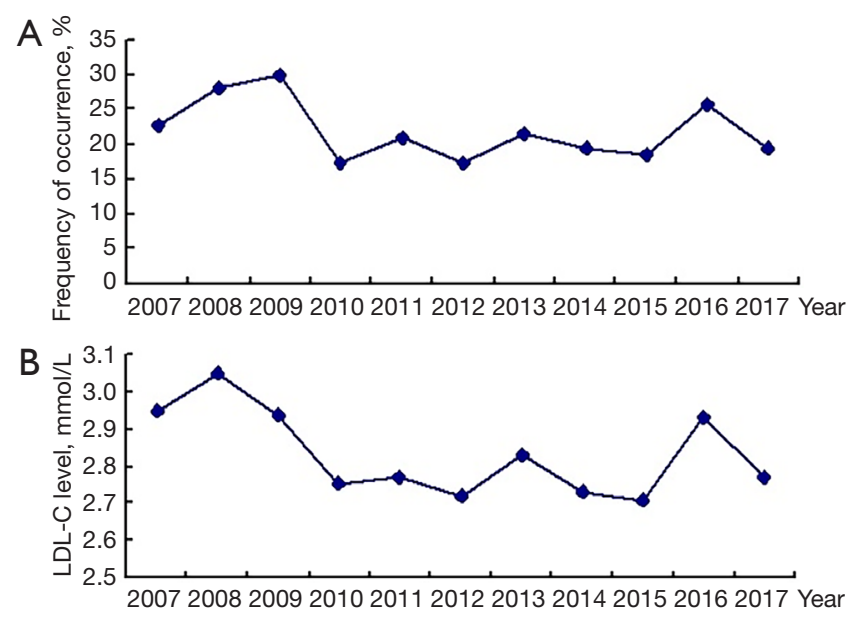

Figure 1 Trends in LDL-C level and elevated LDL-C during a first acute myocardial infarction in young men 18 to 44 years old between 2007 and 2017. (A) Trends in the prevalence of elevated LDL-C, the prevalence of elevated LDL-C decreased from 2007 to 2017 , but didn't show a downward trend among those patients $(\mathrm{P}$ trend =0.068); (B) trends in LDL-C level, the mean LDL-C didn't show a linear correlation with the time of admission $(\beta=-0.019$, $\mathrm{P}=0.092$ ).

Recent reports have confirmed that mean LDL-C levels have shown a linear increase over time, from $2.12 \mathrm{mmol} / \mathrm{L}$ in 2002 to $2.78 \mathrm{mmol} / \mathrm{L}$ in 2010 and to $2.87 \mathrm{mmol} / \mathrm{L}$ in 2015 (8). Over the same period, the frequency of elevated LDL-C increased 2-4 times in the general population of China aged 18 years and over $(8,11)$. Data from Chinese chronic disease RF surveillance showed high TC (28.5\%) and high LDL-C (26.3\%) (based on threshold values: TC $\geq 5.2 \mathrm{mmol} / \mathrm{L}$ and LDL-C $\geq 3.4 \mathrm{mmol} / \mathrm{L}$ ) were the most common components of the dyslipidemia associated with increased CVD risk (11). However, the trend of increasing TC and LDL-C levels were not seen in the young coronary heart disease patients of the current study. In a retrospective study of coronary artery disease patients aged $\leq 45$ years conducted from 2010 to 2014, LDL-C levels showed a downward trend (12). The differences in the conclusions of these studies may be related to the differences in research objects and sample sizes. In the current study, the LDL-C levels and prevalence of elevated LDL-C decreased between 2007 and 2017 although no downward trend was shown among young patients with a first hospitalization for AMI. These patients had a high prevalence of elevated LDL-C. Special attention should therefore be paid to those under 35 years who tend to have a much higher LDL-C level

\section{Zhang et al. Trends in low-density lipoprotein cholesterol level}

and prevalence of elevated LDL-C than patients aged 35-44 years. Overweight and obesity due to lifestyle may be the main cause of dyslipidemia in young people under 35 years. Recent national representative surveys have shown that the frequencies of elevated TC and LDL-C were $4.3 \%$ and $2.4 \%$, respectively, for adults aged $35-74$ years. Elevated cholesterol levels were more common among men and those younger than the 55-64 years age group (13).

Low awareness of elevated TC or LDL-C status was found among young adults with a first AMI. Only $4.2 \%$ of individuals were aware of their condition, a lower rate of awareness than that of the general population 10 years ago. Figures from 2010 show the awareness rate for dyslipidemia ( $\mathrm{TC} \geq 6.22 \mathrm{mmol} / \mathrm{L}, \mathrm{TG} \geq 2.26 \mathrm{mmol} / \mathrm{L}, \mathrm{HDL}-\mathrm{C}$ $<1.04 \mathrm{mmol} / \mathrm{L}$, or LDL-C $\geq 4.14 \mathrm{mmol} / \mathrm{L}$ ) in the general Chinese population aged 20 and older was $10.3 \%$ in 2010 and the stratified rate was $6.0 \%$ in groups aged $<45$ years (14). Lower rates of awareness correlate with poorer rates of action towards treatment. Thus, these results highlight the pressing need for public education regarding blood lipid monitoring and the requirement to improve general awareness about dyslipidemia.

In the case of young adults, priority should be given to estimation of total ASCVD risk and lifetime risk in order to engage primary prevention. Thereafter, an appropriate LDL-C level should be maintained according to risk stratification. Current guidelines on the management of serum cholesterol recommend an appropriate LDL-C concentration of $<1.8 \mathrm{mmol} / \mathrm{L}$ $(70 \mathrm{mg} / \mathrm{dL})$ for a population at high risk of ASCVD (15). For the general population, including those at low risk of ASCVD, LDL-C concentration $<2.6 \mathrm{mmol} / \mathrm{L}$ was considered desirable with under $3.4 \mathrm{mmol} / \mathrm{L}$ an acceptable level according to Chinese and American guidelines $(16,17)$. The results of the current study show that LDL-C levels correlated with the degree of coronary artery stenosis. An LDL-C concentration $\geq 3.4 \mathrm{mmol} / \mathrm{L}$ was associated with increased risk of coronary artery stenosis. A 20-year follow up study conducted in Chinese adults aged 35-64 years, demonstrated that the lower the LDL-C concentration within the range 1.8 to $4.1 \mathrm{mmol} / \mathrm{L}$, the lower the long-term ASCVD risk. The study concluded that an LDL-C concentration within the range 1.8 to $2.6 \mathrm{mmol} / \mathrm{L}$ is appropriate for the general population to achieve primary prevention (18). Most of the young adults included in the present study would be classified as low risk, based on traditional ASCVD risk prediction scores, even taking into account a lifetime risk estimate (16). 
Thus, we recommend that young adults who have at least 2 out of 5 conventional RFs (hypercholesterolemia, hypertension, diabetes, obesity, or smoking) and are currently classified as low risk should be considered as intermediate risk in clinical practice and given access to appropriate primary preventative strategies. An appropriate LDL-C concentration of $2.6 \mathrm{mmol} / \mathrm{L}$ or below should be maintained (15). The current study has also highlighted the combination of smoking, accompanied by hypertension, obesity, or elevated LDL-C, as the most common combination of RFs. Reducing LDL-C level translates into a greater absolute risk reduction for a person with increasing numbers of RFs or with higher risk of ASCVD.

Young patients with a first hospitalization for AMI should take appropriate action, including both lifestyle changes and optimal medical therapy, to reduce LDL-C concentrations to below $1.4 \mathrm{mmol} / \mathrm{L}(15)$. Among the participants in the current study, only $3.6 \%$ had an LDL-C concentration of $<1.4 \mathrm{mmol} / \mathrm{L}$. Treatment should be initiated with statins in most cases, since there is ample evidence that statins decrease the progression of CVD (19). Previous studies of coronary atherosclerosis involving statin-treated patients have consistently demonstrated that the progression of coronary atherosclerotic plaque volume can be arrested if an LDL-C concentration of below $1.8 \mathrm{mmol} / \mathrm{L}$ is achieved (7). However, this optimal target of an LDL-C concentration of below $1.8 \mathrm{mmol} / \mathrm{L}$ is seldom achieved. Rates of achievement of the target are $15.3-36.1 \%$ among patients with CHD in China $(11,20,21)$. Thus, current guidelines recommend that for patients at very-high or persistent high-risk despite being treated with a maximally tolerated statin, treatment should be combined with ezetimibe. If the goal LDL-C concentration is still not reached, additional treatment with a PCSK9 inhibitor should be indicated (15-17).

Our study has several potential limitations. First, the single center nature of the study limited the available sample size. Second, since this was a retrospective analysis, there is a lack of detailed data regarding health behaviors, such as physical activity, sleep duration, emotion, and stress. Thus, the associations between LDL-C level and coronary artery stenosis have been made without adjustment for these factors. Third, the sample of annual AMI hospitalizations was small and this may have influenced trends over time.

In conclusion, our study revealed that young Chinese adults hospitalized with a first AMI had a high prevalence of elevated LDL-C concentrations but low awareness of their dyslipidemic status, and this led to a heavy burden of ASCVD. Special attention should be paid to those under the age of 35 , since they had more serious conditions than those aged 35-44. The LDL-C level and prevalence of elevated LDL-C remained unchanged over the years included in our study [2007-2017]. An LDL-C concentration of $3.4 \mathrm{mmol} / \mathrm{L}$ or above is associated with increased risk of coronary artery stenosis. More than $60 \%$ of patients surveyed had at least 2 RFs. We recommend that young adults who have at least 2 out of 5 conventional RFs (hypercholesterolemia, hypertension, diabetes, obesity, or smoking) and are classified as low risk should be considered intermediate risk in clinical practice with regard to planning appropriate primary preventative strategies. The LDL-C concentrations should be maintained below $2.6 \mathrm{mmol} / \mathrm{L}$. An LDL-C concentration of under $3.4 \mathrm{mmol} / \mathrm{L}$ is recommended for those with 0-1 conventional RFs to achieve primary prevention.

\section{Acknowledgments}

The authors wish to thank postgraduates (Haoran Xing, Xueyao Yang, Xin Zhao, Wenyi Yang, Xiangru Li) of the Department of Cardiology, Beijing Anzhen Hospital, for extracting data from the electronic records. The authors would like to express their gratitude to EditSprings (https:// www.editsprings.com/) for the expert linguistic services provided.

Funding: Cardiovascular precision medicine, funded by Beijing Municipal Science and Technology (PXM2018_014226_000013).

\section{Footnote}

Reporting Checklist: The authors have completed the STROBE reporting checklist. Available at https://dx.doi. org/10.21037/atm-21-4480

Data Sharing Statement: Available at https://dx.doi. org/10.21037/atm-21-4480

Conflicts of Interest: All authors have completed the ICMJE uniform disclosure form (available at https://dx.doi. org/10.21037/atm-21-4480). The authors have no conflicts of interest to declare.

Ethical Statement: The authors are accountable for all aspects of the work in ensuring that questions related to the accuracy or integrity of any part of the work are appropriately investigated and resolved. All procedures 
performed in this study involving human participants were in accordance with the Declaration of Helsinki (as revised in 2013). This study was approved by Beijing Anzhen Hospital Ethics Committee (2020049X). Individual consent for this retrospective analysis was waived.

Open Access Statement: This is an Open Access article distributed in accordance with the Creative Commons Attribution-NonCommercial-NoDerivs 4.0 International License (CC BY-NC-ND 4.0), which permits the noncommercial replication and distribution of the article with the strict proviso that no changes or edits are made and the original work is properly cited (including links to both the formal publication through the relevant DOI and the license). See: https://creativecommons.org/licenses/by-nc-nd/4.0/.

\section{References}

1. Zhou M, Wang H, Zeng X, et al. Mortality, morbidity, and risk factors in China and its provinces, 1990-2017: a systematic analysis for the Global Burden of Disease Study 2017. Lancet 2019;394:1145-58.

2. Sun JY, Liu J, Xie XQ, et al. Surveillance on the incidence of acute coronary events in the permanent residents of Beijing aged 25 years and more from 2007 to 2009. Zhonghua Xin Xue Guan Bing Za Zhi 2012;40:194-8.

3. Zhang Q, Zhao D, Xie W, et al. Recent Trends in Hospitalization for Acute Myocardial Infarction in Beijing: Increasing Overall Burden and a Transition From ST-Segment Elevation to Non-ST-Segment Elevation Myocardial Infarction in a Population-Based Study. Medicine (Baltimore) 2016;95:e2677.

4. Gao XJ, Yang JG, Yang YJ, et al. Age-related coronary risk factors in Chinese patients with acute myocardial infarction. Zhonghua Yi Xue Za Zhi 2016;96:3251-6.

5. Zhao D, Liu J, Wang M, et al. Epidemiology of cardiovascular disease in China: current features and implications. Nat Rev Cardiol 2019;16:203-12.

6. Gu X, Yang X, Li Y, et al. Usefulness of Low-Density Lipoprotein Cholesterol and Non-High-Density Lipoprotein Cholesterol as Predictors of Cardiovascular Disease in Chinese. Am J Cardiol 2015;116:1063-70.

7. Ference BA, Ginsberg HN, Graham I, et al. Low-density lipoproteins cause atherosclerotic cardiovascular disease. 1. Evidence from genetic, epidemiologic, and clinical studies. A consensus statement from the European Atherosclerosis Society Consensus Panel. Eur Heart J 2017;38:2459-72.

8. Song PK, Man QQ, Li H, et al. Trends in Lipids Level and Dyslipidemia among Chinese Adults, 2002-2015. Biomed Environ Sci 2019;32:559-70.

9. Silverman MG, Ference BA, Im K, et al. Association Between Lowering LDL-C and Cardiovascular Risk Reduction Among Different Therapeutic Interventions: A Systematic Review and Meta-analysis. JAMA 2016;316:1289-97.

10. Thygesen K. 'Ten Commandments' for the Fourth Universal Definition of Myocardial Infarction 2018. Eur Heart J 2019;40:226.

11. Zhang M, Deng Q, Wang L, et al. Prevalence of dyslipidemia and achievement of low-density lipoprotein cholesterol targets in Chinese adults: A nationally representative survey of 163,641 adults. Int J Cardiol 2018;260:196-203.

12. Wang $\mathrm{X}$, Gao $\mathrm{M}$, Zhou $\mathrm{S}$, et al. Trend in young coronary artery disease in China from 2010 to 2014: a retrospective study of young patients $\leq 45$. BMC Cardiovasc Disord 2017;17:18.

13. Xi Y, Niu L, Cao N, et al. Prevalence of dyslipidemia and associated risk factors among adults aged $\geq 35$ years in northern China: a cross-sectional study. BMC Public Health 2020;20:1068.

14. Li JH, Wang LM, Mi SQ, et al. Awareness rate, treatment rate and control rate of dyslipidemia in Chinese adults, 2010. Zhonghua Yu Fang Yi Xue Za Zhi 2012;46:687-91.

15. Mach F, Baigent C, Catapano AL, et al. 2019 ESC/EAS Guidelines for the management of dyslipidaemias: lipid modification to reduce cardiovascular risk. Eur Heart J 2020;41:111-88.

16. Joint Committee for Developing Chinese guidelines on Prevention and Treatment of Dyslipidemia in Adults. (2016) Chinese guidelines on prevention and treatment of dyslipidemia in adults (2016 revision). Zhonghua Xin Xue Guan Bing Za Zhi 2016;44:833-53.

17. Grundy SM, Stone NJ, Bailey AL, et al. 2018 AHA/ ACC/AACVPR/AAPA/ABC/ACPM/ADA/AGS/APhA/ ASPC/NLA/PCNA Guideline on the Management of Blood Cholesterol: A Report of the American College of Cardiology/American Heart Association Task Force on Clinical Practice Guidelines. J Am Coll Cardiol 2019;73:e285-350.

18. Zhang X, Liu J, Wang M, et al. Twenty-year epidemiologic study on LDL-C levels in relation to the risks of atherosclerotic event, hemorrhagic stroke, and cancer death among young and middle-aged population in China. J Clin Lipidol 2018;12:1179-1189.e4.

19. Wilson PWF, Polonsky TS, Miedema MD, et al. 
Systematic Review for the 2018 AHA/ACC/AACVPR/ AAPA/ABC/ACPM/ADA/AGS/APhA/ASPC/NLA/

PCNA Guideline on the Management of Blood Cholesterol: A Report of the American College of Cardiology/American Heart Association Task Force on Clinical Practice Guidelines. J Am Coll Cardiol 2019;73:3210-27.

20. Zheng W, Zhang YJ, Bu XT, et al. LDL-cholesterol goal attainment under persistent lipid-lowering therapy in northeast China: Subgroup analysis of the dyslipidemia

Cite this article as: Zhang M, Zuo HJ, Yang HX, Nan N, Zhang D, Song XT. Trends in low-density lipoprotein cholesterol level among Chinese young adults hospitalized with first acute myocardial infarction. Ann Transl Med 2021;9(20):1536. doi: 10.21037/atm-21-4480 international study of China (DYSIS-China). Medicine (Baltimore) 2017;96:e8555.

21. Xing Y, Liu J, Hao Y, et al. Prehospital statin use and low-density lipoprotein cholesterol levels at admission in acute coronary syndrome patients with history of myocardial infarction or revascularization: Findings from the Improving Care for Cardiovascular Disease in China (CCC) project. Am Heart J 2019;212:120-8.

(English Language Editor: J. Jones) 
Supplementary

Table S1 The top 3 components across the status of risk factors cluster

\begin{tabular}{|c|c|c|c|c|}
\hline $\begin{array}{l}\text { The top } 3 \\
\text { components }\end{array}$ & $\begin{array}{l}\text { One RF only } \\
\qquad(n=846)\end{array}$ & Two RFs only $(n=954)$ & Three RFs only $(n=601)$ & Four RFs only $(n=160)$ \\
\hline First & $\begin{array}{c}\text { Smoking, } 543 \\
(64.2)\end{array}$ & $\begin{array}{c}\text { Smoking }+ \text { hypertension, } 285 \\
(29.9)\end{array}$ & $\begin{array}{c}\text { Smoking + hypertension + } \\
\text { obesity, } 220 \text { (36.6) }\end{array}$ & $\begin{array}{c}\text { Smoking + elevated LDL-C + } \\
\text { hypertension + obesity, } 66 \text { (41.3) }\end{array}$ \\
\hline Second & $\begin{array}{c}\text { Hypertension, } 128 \\
\text { (15.1) }\end{array}$ & Smoking + obesity, 262 (27.5) & $\begin{array}{c}\text { Smoking + elevated LDL-C + } \\
\text { obesity, } 108(18.0)\end{array}$ & $\begin{array}{c}\text { Smoking + hypertension + diabetes } \\
\text { + obesity, } 65(40.6)\end{array}$ \\
\hline
\end{tabular}

Data are presented as $n$ (\%). RFs, risk factors; LDL-C, low-density lipoprotein cholesterol. 